University of Montana

ScholarWorks at University of Montana

Physical Therapy and Rehabilitation Science

Faculty Publications

Physical Therapy and Rehabilitation Science

1995

\title{
Afferent Convergence from Divergent Sources Appears to Enhance the Spastic Patient's Ability to Inhibit Antagonist Motoneurons During an Agonist Contraction
}

\author{
Charles Leonard \\ University of Montana - Missoula, charles.leonard@umontana.edu \\ P. M. Diedrich \\ T. Matsumoto \\ G. Kerr
}

Follow this and additional works at: https://scholarworks.umt.edu/ptrs_pubs

Part of the Rehabilitation and Therapy Commons

Let us know how access to this document benefits you.

\section{Recommended Citation}

Leonard, Charles; Diedrich, P. M.; Matsumoto, T.; and Kerr, G., "Afferent Convergence from Divergent Sources Appears to Enhance the Spastic Patient's Ability to Inhibit Antagonist Motoneurons During an Agonist Contraction" (1995). Physical Therapy and Rehabilitation Science Faculty Publications. 8. https://scholarworks.umt.edu/ptrs_pubs/8

This Article is brought to you for free and open access by the Physical Therapy and Rehabilitation Science at ScholarWorks at University of Montana. It has been accepted for inclusion in Physical Therapy and Rehabilitation Science Faculty Publications by an authorized administrator of ScholarWorks at University of Montana. For more information, please contact scholarworks@mso.umt.edu. 


\section{References}

' Winstein CJ. Knowledge of results and motor learning: implications for physical therapy. Phys Ther. 1991:71:140-149.

2 Swanson LR, Lee TD. Effects of aging and schedules of knowledge of results on motor learning. J Gerontol. 1992;47:P406-P411.

' Haaland KY, Harrington D, Yeo R. The effects of task complexity in left and right CVA patients. Neuropsychologia. 1982;25:783-794.

4 Jones RD, Donaldson IM, Parkin PJ. Impairment and recovery of ipsilateral sensory-motor function following unilateral cerebral infarction. Brain. 1989;112:113-132.

s Smutok MA, Grafman J, Salazar AM, Sweeney JK, Jonas BS, DiRocco PJ. Effects of unilateral brain damage on contralateral and ipsilateral upper extremity function in hemiplegia. Phys Ther. 1989;69:195-203.

- Winstein CJ, Schmidt RA. Reduced frequency of knowledge of results enhances motor skill learning. Journal of Experimental Psychology: Learning, Memory, and Cognition. 1990;16:677-691.

7 Sparrow WA, Summers JJ. Performance on trials without knowledge of results $(\mathrm{KR})$ in reduced relative frequency presentations of KR. $J$ Motor Behavior. 1992;24:197-209.

- Schmidt RA, Shapiro DC. Optimizing Feedback Utilization in Motor Skill Training (Report No. 1/86). Alexandria, Va: US Army Research Institute (Basic Research); 1986.

- Sherwood DE. Effect of bandwidth knowledge of results on movement consistency. Perceptual \& Motor Skills. 1988;66:535-542.

\section{Afferent Convergence from Divergent Sources Appears to Enhance the Spastic Patient's Ability to Inhibit Antagonist Motoneurons During an Agonist Contraction}

Leonard CT, Diedrich PM, Matsumoto T, Kerr G. Physical Therapy Dept, University of Montana, Missoula, MT 59812. Funding provided by The National Institutes of Health (1R15NS3066401A1; 4X-5925), MJ Murdock Foundation, The University of Montana.

Spasticity and excessive muscular cocontraction during movement are common impairments following upper motor neuron (UMN) lesions. For example, during voluntary ankle dorsiflexion, individuals with spastic type cerebral palsy (CP) do not inhibit the antagonist triceps surae motoneuron pool. This lack of reciprocal inhibition has been attributed, in part, to a supraspinal deficit. ${ }^{1}$ It has also been suggested that individuals with $\mathrm{CP}$ have changes in spinal cord circuitry that may contribute to their movement impairments. ${ }^{2-1}$ Others have suggested that the cocontraction that occurs during voluntary movement of individuals with $\mathrm{CP}$ is secondary to aberrant corticospinal projections that project concomitantly to agonist and antagonist muscles, such that each cannot be activated without the other. ${ }^{5}$

Voluntary movement presumedly originates in associational areas of the sensorimotor cortex, whereas automatic movements are triggered by peripheral afferents involving the vestibular, somatosensory, and visual systems. Comparing antagonist muscle alpha motoneuron modulations during voluntary and automatic movement might reveal the relative contributions of the various mechanisms proposed for excessive cocontraction following UMN damage. A series of experiments examined alpha motoneuron activity of the soleus muscle during voluntary and postural perturbation-induced activations of the tibialis anterior muscle.
$\mathrm{H}$-reflexes were recorded from the soleus muscle using a repetitive stimulation methodology described in a previous publication.' Recordings were made during voluntary ankle dorsiflexions and during dorsiflexions elicited by a posterior to anterior translation of a balance platform (Custom design; Porcella/Leonard). Surface EMG recordings (Therapeutics Unlimited) of the tibialis anterior and soleus were also obtained. Leg, ankle, and platform movements were recorded with a three-dimensional motion analysis system (4 camera; $200 \mathrm{~Hz}$ Motion Analysis Co). H-reflex, sEMG, and kinematic data were interfaced and analyzed via a Sun Station computer system. Four subject populations were examined: (1) individuals with CP (age range 18 to 45), (2) age-equivalent nondisabled controls (age range 21 to 45 years), (3) individuals with adult-onset cerebral vascular accidents (CVA) (age range 54 to 73 years), and (4) nondisabled, older age-equivalent controls (age range 65 to 78 years).

All nondisabled subjects, regardless of age, inhibited the soleus alpha motoneuron pool prior to tibialis anterior activation during voluntary ankle dorsiflexion. All subjects, regardless of age, inhibited soleus alpha motoneurons during automatic movements. There were differences in response characteristics between younger and older control subjects that will not be addressed in this paper. Individuals with $\mathrm{CP}$ and CVA did not inhibit the soleus muscle during voluntary ankle dorsiflexions. In general, these subjects did not inhibit the soleus during ankle dorsiflexions induced by postural perturbations either (Figure 1). There were exceptions, however, to this general finding. Under certain circumstances, CVA subjects and, to a lesser extent, individuals with $\mathrm{CP}$, exhibited inhibition of the soleus muscle during automatic perturbations (Figure 2). Kinematic analysis of these trials revealed that subjects had been pushed into an initial plantarflexion that exceeded 90 degrees, had unweighted the limb, and had a strong activation of the TA muscle. None of these conditions alone appeared to be sufficient to elicit soleus muscle inhibition. Only when all three conditions were met did inhibition occur.

These results are preliminary and, at the present state of analysis, are tentative at best. Yet the results are provocative enough to warrant an attempt at explanation. The ability of afferent input to modulate motor output has been known for quite some time. ${ }^{0.7}$ In humans, however, it had previously been hypothesized that postural perturbations triggered stereotyped kinematic and muscle activation patterns that could be described by a finite set of synergies or strategies (eg, ankle or hip strategy). ${ }^{8}$ It has now been shown that automatic postural reactions vary dependent on initial position of the body, ground reaction forces, kinetics, type of stimulation, and a multitude of other afferent information..$^{911}$ The CNS appears to modulate its output in response to such kinematic information as joint angle (stationary and dynamic), direction of movement, and the speed of angular changes. ${ }^{12}$ It is important to remember that kinesthesia is composed of multisensory interaction. This interaction is accomplished by convergent input onto a common neural target (such as an interneuron or motoneuron) from divergent sources that include supraspinal 
Figure 1. Graphic representation of one, 2-second trial. The subject, a 23-year-old female with spastic type cerebral palsy with quadriplegic involvement, activated the tibialis anterior muscle (TA) is response to a posterior to anterior translation of the balance platform. The soleus $\mathrm{H}$-reflex $(\mathrm{H})$ increased. During similar conditions, nondisabled subjects inhibit the soleus $\mathrm{H}$-reflex.

\section{AUTOMATIC: 23 Y/O-CP-QUADRIPLEGIA}

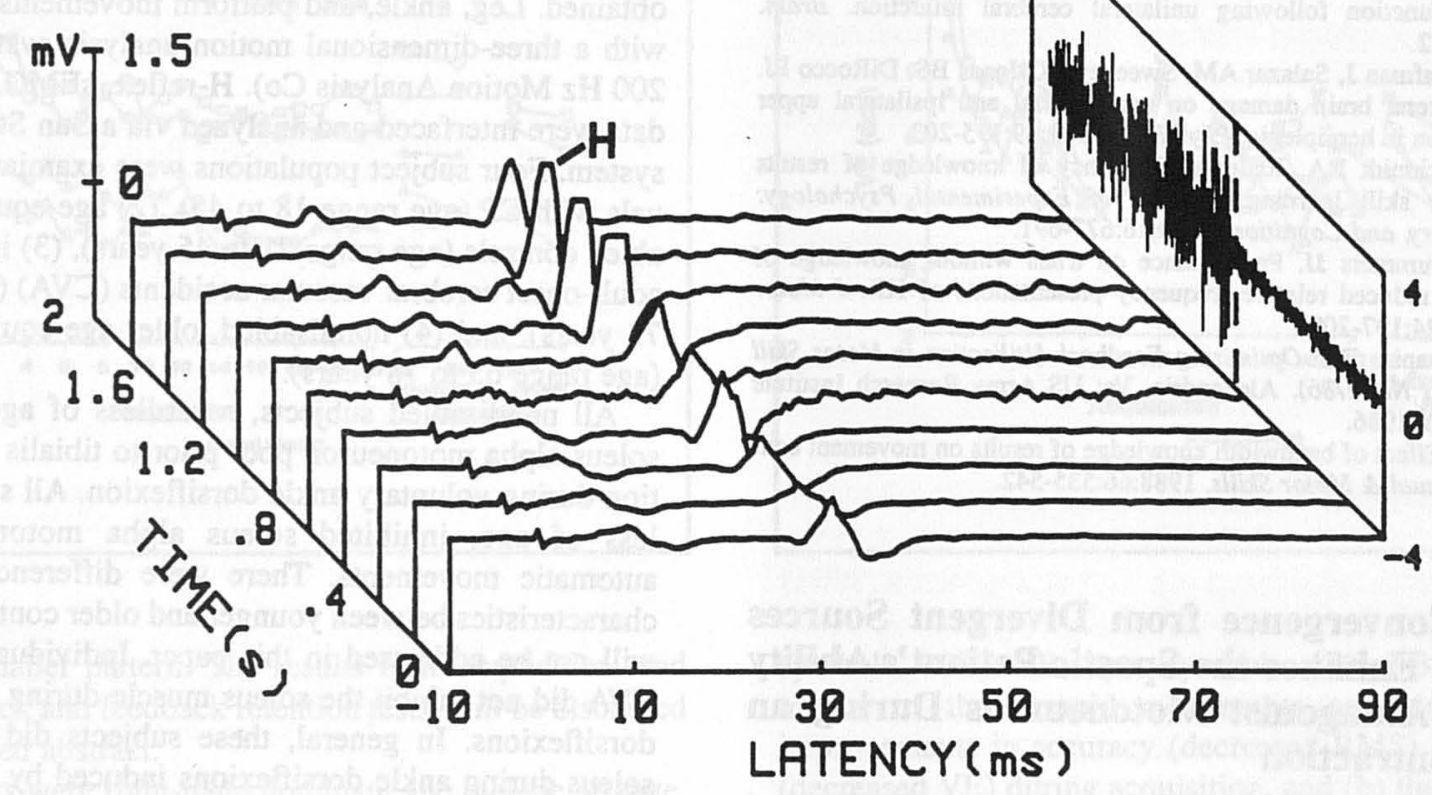

TA

Figure 2. Same subject and same condition as per Figure 1, but in this trial the subject had inhibition of the soleus H-reflex following TA activation. Kinematic analysis of this trial indicated that the subject had unweighted the limb, and was initially pushed into plantarflexion.

\section{AUTOMATIC: 23 Y/O-CP-QUADRIPLEGIA}

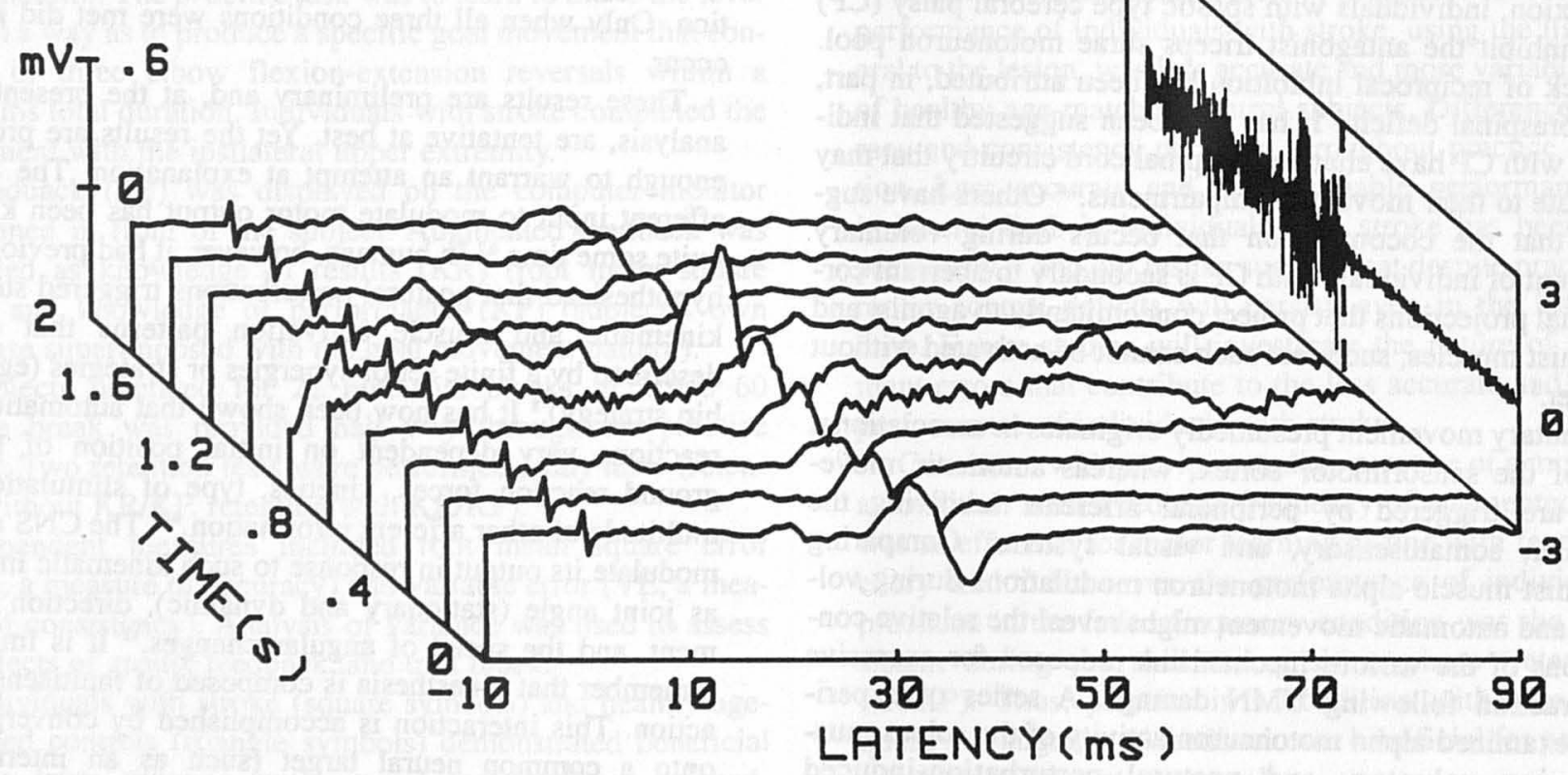


and peripheral afferent projections. For instance, the Ia inhibitory interneuron, which mediates disynaptic reciprocal inhibition, receives convergent input from Ia and Ib afferents, Renshaw cells, and supraspinal projections. ${ }^{13}$ Afferents from cutaneous receptors, spindles, and golgi tendon organs, together with supraspinal input, converge onto alpha motoneurons. ${ }^{14,15}$ These afferents respond to passive and active movements and can inhibit or excite alpha motoneurons. ${ }^{16}$ Tonic peripheral afferent input summates with supraspinal inputs to bias motor responses in one direction or another. Mastication provides an example of the motoric effects of summation. Subthreshold cortical stimulation to areas innervating muscles of mastication does not elicit muscular contractions. Distending the jaw does not evoke mastication. Distending the jaw concomitant with subthreshold cortical stimulation, however, does evoke mastication."

Perhaps the tonic or dynamic supraspinal input of individuals with UMN damage is compromised so that greater than normal afferent input is needed to trigger reciprocal inhibition. Changing pressure on the sole of the foot (unweighting), increasing stretch of the TA (increased ankle excursion into plantarflexion), and enhanced TA activity might summate to provide additional drive and therefore trigger an appropriate response. There are human and nonhuman animal data to support this hypothesis. Unweighting of the limb during a postural perturbation increases TA activity in humans ${ }^{17}$ and initiates flexion in spinal cats. ${ }^{18}$ Increased ankle plantarflexion during a postural perturbation in humans increases activity in the TA. ${ }^{19}$ Hip extension initiates swing phase in spinal cats. ${ }^{6}$

Clinicians might want to try to make use of this information when treating patients with UMN damage. Therapists are already well aware of the effects of increasing afferent input to a muscle by stroking, tapping, or applying a quick stretch in order to enhance a voluntary contraction. The findings reported in the previous paragraphs suggest that a multitude of other afferent input might also be effective. Changing the kinematics or kinetics at one joint might have an effect on the joint immediately involved and at other joints and muscles involved in a multijoint movement. Further experimentation and clinical trials are needed to determine the most efficacious combination of afferent input. It is very likely that different afferent input will have various effects dependent on the task desired and the position of the body at the time of movement initiation.

\section{References}

'Leonard CT, Moritani T, Hirschfeld H, Forssberg H. Deficits in reciprocal inhibition in children with cerebral palsy as revealed by $\mathrm{H}$ reflex testing. Dev Med Child Neurol. 1990;32:974-984.

${ }^{2}$ Harrison A. Spastic cerebral palsy: possible spinal interneuronal contributions. Dev Med Child Neurol. 1988;30:769-780.

${ }^{3}$ Myklebust BM, Gottlieb GL, Penn RD, Agarwal GC. Reciprocal excitation of antagonistic muscles as a differentiating feature in spasticity. Ann Neurol. 1982;12:367-374.

'Leonard CT. Neural and neurobehavioral changes associated with perinatal brain damage. In: Forssberg H, Hirschfeld H, eds. Movement Disorders in Children. Amsterdam: Karger; 1992:50-56.

${ }^{3}$ Brouwer B, Ashby P. Corticospinal projections to lower limb motoneurons in man. Exp Brain Res. 1992;89:649-654.
'Andersson O. Peripheral control of the cat's step cycle. Acta Physiol Scand. 1981;113:80-101.

'Forssberg H, Grillner S, Rossignol S. Phasic gain control of reflexes from the dorsum of the paw during spinal locomotion. Brain Res. 1977;132:121139.

'Nashner LM, McCollum G. The organization of human postural movements: a formal basis and experimental synthesis. Behav Brain Sci. 1985;8:135-172.

${ }^{9} \mathrm{Hirschfeld} \mathrm{H}$, Forssberg H. Phase-dependent modulations of anticipatory postural activity during human location. J Neurophysiol. 1991;66:

${ }^{10}$ Lacquaniti F. Automatic control of limb movement and posture. Curr Opin Neurobiol. 1992;2:807-814.

" Rossignol S, Lund JP, Drew T. The role of sensory inputs in regulating patterns of rhythmical movements in higher vertebrates: a comparison between locomotion, respiration and mastication. In: Cohen AH, Rossignol S, Grillner S, eds. Neural Control of Rhythmic Movements in Vertebrates. New York, NY: John Wiley \& Sons; 1988:201-284.

12 Burgess PR, Wei JY. Signaling of kinesthetic information by peripheral sensory receptors. Ann Rev Neurosci. 1982;5:171-187.

${ }^{13}$ Jankowska E. Interneuronal relay in spinal pathways from proprioceptors. Prog Neurobiol. 1992;38:335-378.

14 Baldissera F, Hultborn H, Illert M. Integration in spinal neuronal systems. In: Brooks VB, ed. Handbook of Physiology: The Nervous System II. Baltimore, Md: Williams \& Wilkins; 1981:509-595.

is Burke D, Gracies JM, Mazevet D, Meunier S, Pierrot-Deseilligny E. Convergence of descending and various peripheral inputs onto common propriospinal-like neurones in man. Physiol. 1992;449:655-671.

${ }^{16}$ Aniss AM, Gandevia SC, Burke D. Reflex responses in active muscles elicited by stimulation of low-threshold afferents from the human foot. $J$ Neurophysiol. 1992;67:1375-1384.

17 Do MC, Bussel B, Breniere Y. Influence of plantar cutaneous afferents on early compensatory reactions to forward fall. Exp Brain Res. 1990;79:319324.

is Pearson KG, Ramirez JM, Jiang W. Entrainment of the locomotor rhythm by group Ib afferents from ankle extensor muscles in spinal cats. Exp Brain Res. 1992;90(3):557-566.

19 Nashner LM. Balance adjustments of humans perturbed while walking. $J$ Neurophysiol. 1980;44:650-664.

\section{Symmetry and Muscle Sequencing During Sit to Stand: A Comparison of Subjects With and Without Hemiplegia}

Carpenter CW, Evans CL, Crispell KF, Kirchhoff AK, Mountain JD, Wilson LE. Shenandoah University-Winchester Medical Center Program in Physical Therapy, Winchester, VA.

The ability to transition from sit to stand is a requirement for many activities of daily living and is one of the most commonly used functional goals for patients with hemiplegia. ${ }^{1}$ It has been suggested that in rising from a chair, body weight is distributed evenly across both lower extremities in persons without hemiplegia and unevenly toward the affected side in persons with hemiplegia. ${ }^{2}$ Studies by Engardt and Vander Linden have demonstrated that persons with hemiplegia do exhibit asymmetrical lower extremity weight-bearing during the entire sit-to-stand movement. ${ }^{1.2}$ Unfortunately, there are minimal objective data on the asymmetry of weight distribution or muscle activity that occurs during sit to stand in patients with hemiplegia. The purpose of this study was to identify critical variables that differentiate subjects with and without hemiplegia during the sit-to-stand task. Our hypothesis was that there would be a significant difference in muscle activation pattern and symmetry in the task of sit to stand between two groups. 